\title{
Employees Relevancy Following The Emergence of Artificial Intelligence (Al)
}

Nikaela Wilson, Habeebullah Hussaini Syed

To Link this Article: http://dx.doi.org/10.6007/IJARBSS/v11-i9/11245

DOI:10.6007/IJARBSS/v11-i9/11245

Received: 15 July 2021, Revised: 17 August 2021, Accepted: 30 August 2021

Published Online: 22 September 2021

In-Text Citation: (Wilson \& Syed, 2021)

To Cite this Article: Wilson, N., \& Syed, H. H. (2021). Employees Relevancy Following The Emergence of Artificial Intelligence (AI). International Journal of Academic Research in Business and Social Sciences, 11(9), 1692-1701.

\section{Copyright: @ 2021 The Author(s)}

Published by Human Resource Management Academic Research Society (www.hrmars.com)

This article is published under the Creative Commons Attribution (CC BY 4.0) license. Anyone may reproduce, distribute, translate and create derivative works of this article (for both commercial and non-commercial purposes), subject to full attribution to the original publication and authors. The full terms of this license may be seen at: http://creativecommons.org/licences/by/4.0/legalcode

Vol. 11, No. 9, 2021, Pg. 1692 - 1701

Full Terms \& Conditions of access and use can be found at http://hrmars.com/index.php/pages/detail/publication-ethics 


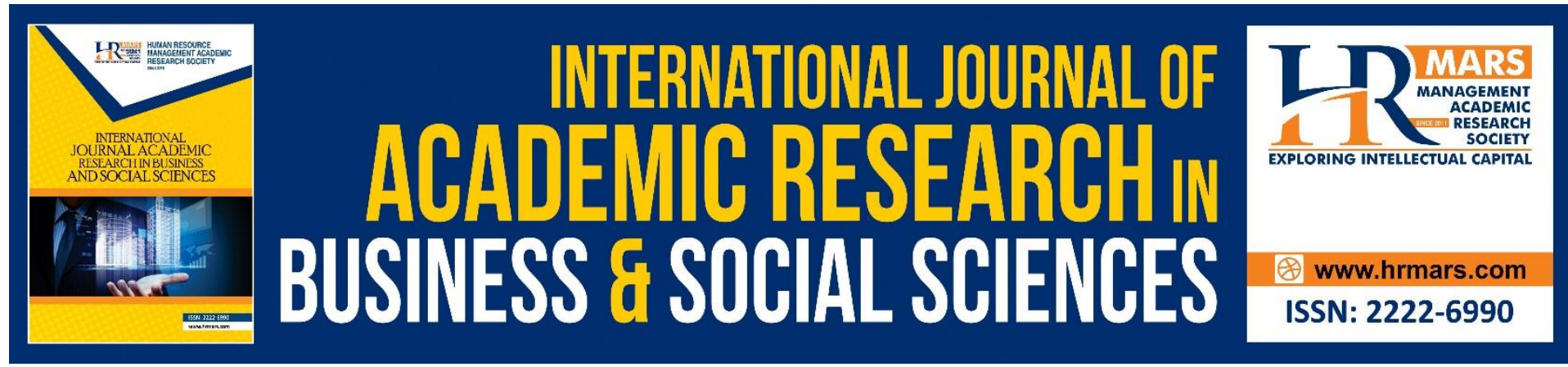

\title{
Employees Relevancy Following The Emergence of Artificial Intelligence (Al)
}

\author{
Nikaela Wilson ${ }^{1}$, Habeebullah Hussaini Syed ${ }^{2}$ \\ Designation, Location: Faculty of Economics, University of Belgrade, Serbia ${ }^{1}$, Sr. Data \\ Engineer, Slalom LLC, NewYork, USA ${ }^{2}$ \\ Email: nikaeyla@hotmail.com ${ }^{1}$, hsyed86844@gmail.com²
}

\begin{abstract}
Artificial Intelligence (AI) is increasingly hijacking human tasks at different organizational levels; thus, employees need to be skilled in various aspects beyond work limitations and prerequisites. The fourth industrial revolution has catapult this into the work space, which encompasses a combination of different technologies that have gradually led to the blurring of lines between both the physical and digital world. It incessantly plays a pivotal role in how job tasks are conducted and has even aided in revamping the structure of the organization. Some authors contended that Al would primarily replace tasks not jobs. This implies that $\mathrm{Al}$ would concentrate more on difficult tasks that may probably require mechanical intelligence. It would furthermore supersede the human labor in analytical intelligence by determining tasks that entail rational thinking skills. With the probability game-changing of digitalization toward dehumanizing people, many areas are needed to unmask the strengths and abilities of employees. While Al experts are incessantly designing machines to imitate human skills including problem-solving, task-execution, to mention a few, it is however useful and reasonable to explore for employees' survival after the widespread emergence of $\mathrm{Al}$ machines. The capability of $\mathrm{Al}$ in data-processing requests for massive employees' concentration on preparing individuals toward understanding data, interpreting results and making decisions. Employees would solely be remembered in the era of Al if extraordinary skills that may not be discharged by Al machines are cultivated. In this regard, this paper attempts to unveil $\mathrm{Al}$ and employees' relevance in addition to the valuable and lucrative areas for employees in the immediate future.
\end{abstract}

Keywords: Artificial Intelligence, Mechanical Intelligence, Employees, Digitalization.

\section{Introduction}

Technology is increasingly influencing global businesses, shaping the nature of work, advancing societies and replacing human beings as it relates to task-fulfilment (Agerfalk, 2020). We are in the $4^{\text {th }}$ industrial revolution, with each industrial revolution characterized by a technological shift. This has contributed to the digitalization of broader areas of the work place as more organizations are embracing the latest technologies. Making machines intelligent. 
There is no doubt that artificial intelligence has revolutionized operations in many industries. Artificial Intelligence is a rapidly evolving technology that has the potential to significantly impact the employment industry in the United States and other countries as well. In contrast to earlier technologies, which had narrow uses in sectors like manufacturing and medical, aspects of Al now have broad applications in highly-skilled, well-paid, and urban industries, such as financial management, health, and information systems. Artificial intelligence applications, particularly digitalization, have major impacts on the labor market. Understanding its effect will be critical in creating policies that encourage efficient labor markets for the benefit of employees, businesses, and society as a whole.

This paper contributes to the ongoing debate, surrounding the Al and employees' relevance in unveiling the valuable and lucrative areas of opportunities for employees in the immediate future. The literature has been organized around these areas; Artificial Intelligence and employees' relevance, Aspects of Al, Human Capital \& Al, Al systems in human resources, Lucrative areas for employees in the immediate future and Concluding comments.

\section{Research Statement}

This paper adopts a theoretical approach which examines previous literature in the area of $\mathrm{Al}$ in relation to eliminating and creating some of today's most valued employment opportunities. Furthermore, it delves into the benefits and draw backs of $A l$ in the course of expanding employee jobs, focusing primarily on relevance and future opportunities for employees.

\section{Objectives}

$>$ The relevance of employees amidst the introduction of Al while simultaneously highlighting some aspects of $\mathrm{Al}$ and Human capital.

$>$ To delve into the benefits and draw backs of Al in the course of expanding employees' jobs.

To highlight some of the lucrative areas of opportunities for employees in the immediate future.

\section{Literature Review}

\section{Artificial Intelligence and Employee Relevance}

Huang et al. (2019) argued that human assignments and mechanical tasks will soon disappear in society in exchange for artificially intelligent machines. Similarly, according to Chaudhuri et al. (2020, as cited by Jaiswal et al., 2021) it was revealed that almost $77 \%$ of the workforce in China and $71 \%$ of the workforce in India have been swapped with Al. Some workers will eventually be replaced in factories by Al machines. For instance, in China, toward reducing the workforce of the country by $90 \%$, a robot-only factory was established in China Dongguan factory city (Mihai, 2017).

Although technology usually improves productivity, Al has the potential to eliminate some of today's most valued employment opportunities. There will be significant differences in the effect of artificial intelligence and automation across different geographical regions, which will have concerns for the working population, urban-rural disparities, and differences in the distribution of income (Chen \& Xu, 2018; Frai \& László, 2021). Skills requirements, career possibilities, and the placement of employees across sectors and professions in both 
developed and developing nations have the potential to be reshaped by artificial intelligence.

Davenport \& Kirby (2016) opined that Al technologies need to be linked with organizational wants and organizational members' skills. Employees' skills toward ensuring Al operations are worthy of focus regarding retaining and maintaining the relevancy of the human resource department in business and the workplace. Toward ascertaining compatibilities of employees with Al technologies, Hancock Lazaroff-Puck \& Rutherford (2020) projected that the upcoming decades will heavily require employees to update their abilities.

\section{Aspects of Al}

In the era of artificial intelligence, data and talent management; technology and IT firm investment is worth considering. Alongside human resources and business organizations, other sectors including the educational sector need reflection in conformity with $\mathrm{Al}$ technologies. While Tschang and Mezquita (2020) claimed that some scholars upheld that Al will increase the rate of unemployment, others argued that $\mathrm{Al}$ is a tool for augmenting available jobs. Furthermore, Jaiswal et al (2021) inferred that recruitment and applicant selection is the most significant aspect that demand Al in the sphere of human resource.

Another aspect that Al changes are on skills relevancy of employees in the labor market. In most cases, technology is developed to accomplish a particular function, thus altering the need for specific job skills. Low-skilled labor jobs will be eliminated in significant part as a result of the transition toward a more Al-dominated work market. Jobs that need a high level of repetitive tasks are the ones that are most susceptible to being affected by this change. The majority of employment generated by the development and expansion of artificial intelligence will require the retraining of existing employees. Skills demand changes as a consequence of these innovative ways of doing things which spread across the sector, affecting occupational skill needs as well as career progress and societal well-being (for instance, effects on employees' social identities) Martens \& Tolan, 2018). When employees lack the required skills that $\mathrm{Al}$ has, they will be rendered irrelevant or redundant in the company.

Automated machines are expected to eliminate manufacturing jobs, agricultural production, food processing, retailing, transportation and logistics, and hospitality, according to the Bureau of Labor Statistics (Abuselidze \& Mamaladze, 2021). If a recession is on the horizon, this trend toward automation may be accelerated as cash-strapped companies seek cost cutting methods.

Organizations will undoubtedly feel the presence of Al when cognitive competencies replace manual and human work. Despite the revolutionary pattern of $\mathrm{Al}$, employees will remain relevant in the search for value-creation and sustainable competitive advantage. In essence, it is quite possible that employees could maintain their relevance in organizationalterritory by upgrading their abilities in tasks that are arduous for Al to handle.

\section{Human Capital \& Al}

Collins (2021) proposed High Commitment Human Resource (HCHR) toward focusing on human capital. HCHR concentrated on developing and investing in capabilities and skills. It creates somewhat of an enabling environment that boosts human capital and resources, which eventually propel competitive advantage (Chadwick \& Flinchbaugh, 2020). The emergence of Al calls for employees' update in analytical, digital, agility, intelligent automation and prognostic modelling. The implication of these updates will be blatantly 
evident in employees' loyalty, motivation and commitment. Toward avoiding technology replacement for all human-employments and positions, Lethal Autonomous Weapons System (LAWS) together with the military $\mathrm{Al}$ arms race were against in the absence of human control (Tegmark, 2015). One of the major logical arguments raised by those opposing LAWS which is an integral of $\mathrm{Al}$ is that life and death affairs should not be given to technology (Leveringhaus, 2018). In 2007, Robert Sparrow disagreed with the endorsement of the use of LAWS. The argument was based on the fact that Al applications won't render anyone responsible for the fault of the robot machine (Sparrow, 2007).

McKinsey Global Institute conducted a study on 800 occupations and 46 countries. In the developed countries, the study discovered that one-fifth of the worldwide workforce will be disturbed by the emergence of Al systems, software and machines (Muro, Maxim \& Whiton, 2019). Similarly, Boston Consulting Group predicted that by 2025 , average workers will be exchanged for robots and Al software. Moreover, Oxford University, in a study, anticipated the coming 20 years as a period of converting nearly $35 \%$ of UK existing jobs to automated systems (Wakefield, 2015). Automated machines have previously substituted physical and routine activities, while in the future time may supersede humans by controlling intellectual activities (Bughin et al., 2017).

Similarly, based on a paper published in the European Patent Office, by the year 2025, it is projected that 26-30 billion of devices will be embedded with softwares, processors and sensors that will be connected to (IoT) Internet of Things. This will allow independent functioning and data sharing among themselves which will facilitate the automation of the business process such as the intellectual jobs that were previously performed by people. They have already been in use in various sectors ranging from areas in manufacture, agriculture, the transportation industry and even health (Meniere, 2017). Furthermore, Frey \& Osborne (2017) examined how susceptible jobs are to computerization for 702 occupations on US labour market by analyzing the number of jobs at risk and the relationship between an occupation's probability of computerization. The estimates revealed that around $47 \%$ of total US employment is in the high-risk category of automation.

\section{Ai Systems in Human Resources}

As Al relates to simplifying tasks, Amla \& Malhotra (2017) revealed that HR departments are increasingly using modern systems and technologies including cloud computing, big data analysis, artificial intelligence among others to efficiently produce results and execute organizational duties. Organizational tasks such as recruitment, screening, interviewing, onboarding, etc. have been largely performed through robot process automation, chatbot and learning machines.

Al has the potential of revolutionizing HR at all levels including benefits, mobility, training, compensation, recruitment, career maintenance and management, to mention a few. It has the capacity of gathering the highest level of talents and values to companies and HR departments. With the aid of $\mathrm{Al}$, human resources departments can use competition market data, internet data analysis and human capital performance indicators to determine growth, thus, ascertain employee's productivity. Al can be a representation of human intelligence and reasoning and certain gaps can be filled by $A l$ in HR. The gaps include:

Social Dialogue Gap: Demotivation, tensions and lack of trust may emerge in the absence of Al technologies that may ensure smooth social dialogue flow. It is fundamentally wrong for a company to operate without promoting effective communication and collaboration among the employees. 
Skills Management: Al could cater for the management of talents and skills in the company, thus, increase staff's motivation and strengthen teams' growth. Al could be used to reduce employees' stress, pressure and suicide.

Recruitment: Companies, workplaces and HR departments need to take into account the competencies of applicants during the recruitment and selection process. This, in turn, can lead the organization towards a success-path. The definition of the required candidates and minimum requirements to be possessed by the applicant can be facilitated through Al. While recruiting employees, manual procedures for interview and selection including telephone, manual registration etc., can be replaced with Al tools and technologies.

Amla \& Malhotra (2017) reported that out of all companies and industries, just 40 per cent are adopting artificial intelligence. The authors divulged that GE, Facebook and SAT organizations use digital technologies while interviewing, screening, identifying and selecting talents for organizations. In the recruitment process, Al could scrutinize the application and update candidates of application-result within a jiffy. Chatbot system is equally beneficial while solving recruitment-process challenges in the organization. De Mendonca et al. (2018) contended that Al can expose the profile of workers and positions for applicants. Nespoli (2004) believed that Al can reduce organizational errors, problem resolution times and human actions. Al manages workplace, HR departments and organization effectively; advances and enhances methods for validating, collecting and sustaining required data by the organization. Furthermore, Reilly (2018) argued that Al machines are more productive than HR teams as the former limit attrition rate and improve employee's retention. Therefore, in essence it may be concluded that Al can act perfectly and accurately within a short time because it thinks, feels, plans and executes tasks without human-interference.

Interview and Screening Process: Evaluating interviewees with word exams and improving candidate's experience make artificial intelligence useful in the interviewing process. With the help of Amy, Clara and Ay software, interviews and meetings can be scheduled.

Lessen Administrative Stress and Burden: Al can be used to relieve stress and burden. The proper implementation of Al technologies reduces the multitasking roles of the human resources department. Apart from the fact that Al heightens the performance of the HR department, it efficiently handles the workload of the organization.

Selecting Candidate: Based on the observation of Rajesh, Kandaswamy \& Rakesh (2018) it was noticed that the right candidates possessing the required skills could be identified through Al technologies.

Hiring Employees: Al-aided technologies can enable the hiring process to be faster and effective. Iqbal (2018) for instance reported that Armour American Company receives nearly 30,000 resumes monthly. To entertain these resumes, Hirevue Al-enabled digital recruitment system was adopted to address the hiring process challenge. The system enables managers to prepare pre-recorded questions for applicants' interviews, invited the qualified ones through mobile or webcam devices, and thus results in hiring suitable candidates. Hence, it is certain that Al technologies help in hiring candidates.

Limit and Prevent Discriminations: Al will help in preventing biased selection and consideration in an organization. Beyond analyzing employment and task descriptions, Al can guarantee translucency at workplaces (Rathi, 2018). Therefore, it is arguable and established that artificial intelligence (AI) could be helpful for continuous improvement in $H R$ departments, workplaces and organizations. 


\section{Lucrative Areas for Employees in the Immediate Future}

The upcoming generations and future employees have unlimited opportunities alongside the advent of Al software, machines, systems and technologies. When it comes to $\mathrm{Al}$, one cannot deny the range of opportunities it offers in different areas. Al shall create jobs, though; its emergence goes hand in hand with the responsibility of updating one's abilities, qualifications and skills. The game-changing opportunities that can be provided by Al include: Machine operator: Employees can be an operator to several machines. Al will undoubtedly introduce machines to many companies, industries and sectors. These machines can only discharge tasks if a human operator is actively involved. Hence, upcoming generations and future employees can learn how to operate these machines toward analyzing a large number of data and completing many assignments. In other words, jobs like engineers, data analytics, technology suppliers, software developers, robot designers etc. will be highly needed and marketable.

Trainers: trainers will also be needed for many technologies, especially, the modern ones. Their job is to ensure that the trainees become experts in operating the technologies. Trainers ascertain that those tasks are performed and achieved perfectly by technologies. It is the responsibility of trainers to reproduce and mimic human attitudes with Al algorithms.

Explainers: This is another opportunity for future employees and upcoming generations. Explainers will provide an avenue for strategists, transparency analyst and context designer as they bring business leaders and technologists nearer to each other. Explainers will assist many executives when machines contradict their personal decisions, thus amount to negative and unwanted results.

Sustainers: include machine relations manager, automation economist and ethicist. They maintain Al systems under their programmed functions such as ensuring that outrageous costs and unexpected accidents are immediately controlled. It is their responsibility to compare and contrast the performances of smart machines from poor machines.

Engineers and Digital analysts: On the individual level, it is blatantly evident that humans are the ones to complement Al technologies because the challenges of technology are mostly handled by a human than a technologist. Digital analyst and engineers will undoubtedly find a rewarding and satisfying opportunity alongside the advent of Al. The growing need for data engineers has been the forefront of discussions.

Experts in math, algorithms, robotics, coding, shall be surpassing and unprecedented in the magnitude of relevancy.

\section{Conclusion}

Instead of raising concerns on the growing Al technologies, it is in every way important to highlight the capacities and incapacities of Al. To cope effectively and productively with Al, humans need exposure, experience, updates training and skills. Al basically aims at complementing and supporting humans in tedious tasks. It also attempts to expand and provide opportunities for people, specifically, generation $\mathrm{Y}$ and $\mathrm{Z}$. Al is a dependent technology that needs human for successful execution of some action, delivery and performance. Its activities will definitely be tracked and determined by humans.

Without a doubt, artificial intelligence has already changed our lives and will continue to do so in the foreseeable future. However, although it is simple to raise concerns about artificial intelligence pushing unemployment numbers into the double digits and ruining employees' relevance, the reality is that the result will be more complex than just putting people out of work or shifting sectors. These findings are consistent with recent technological 
developments documented in the literature. The Al discourse is ongoing, in the future Al may generate new employment opportunities, strengthen the need for current fields of expertise, shape the skills of a contemporary workforce, and even allow for a more rapid recruiting process. However, although most of the discussion surrounding artificial intelligence and the labor market has focused on automation's potential to replace people, it is also important to consider how Al might assist employers to create new jobs or assist job seekers to avoid unemployment in the future. Additionally, many of these occupations will likely deviate from the conventional full-time work paradigm that we are used to nowadays. Instead, more businesses are anticipated to grow their remote labor force and depend on contractors to meet the vast majority of their staff needs in the future.

\section{Contribution}

This paper will make contributions and bring significance to the ongoing debate, surrounding the relevance of $\mathrm{Al}$ in unveiling the valuable and lucrative areas of opportunities for employees in the immediate future. Previous studies differed in terms of objectives, not all previous studies have addressed all areas simultaneously so this paper expands further on this.

The growing understanding of the need for the next generation and unforeseeable technological developments will be valuable for employees in the future. The focus of the government and future leaders should be toward nurturing the talent and encouraging experimentation. This paper focused on some theoretical contribution related to the objectives and the varied views through the narrative review of literature. It is plausible to enhance Science, Technology, Engineering and Mathematics subjects as tomorrow's workspace will be different from the past, providing more Al related opportunities for employees. This paper will make contributions to the literature in the areas of Artificial Intelligence, employee relevance and other lucrative areas for employees. Even though there are drawbacks it provides a better understanding of how Al can be practically implemented and coexist with employees in organizations to enhance performance that can validate its use.

\section{References}

Abuselidze, G., \& Mamaladze, L. (2021). The impact of artificial intelligence on employment before and during pandemic: A comparative analysis. In Journal of Physics: Conference Series (Vol. 1840, No. 1, p. 012040). IOP Publishing.

Ågerfalk, P. J. (2020). Artificial intelligence as digital agency. European Journal of Information Systems, 29(1), 1-8. https://doi.org/10.1080/0960085X.2020.1721947

Amla, M., \& Malhotra, P. M. (2017). Digital Transformation in HR. International Journal of Interdisciplinary and Multidisciplinary Studies (IJIMS), 4(3), 536-544. Retrieved from http://www.ijims.com

Bughin, J., Staun, J., Andersen, J., Schultz-Nielsen, M., Aagaard P., \& Enggaard, T. (2017). Digitally-enabled automation and artificial intelligence: Shaping the future of work in Europe's digital front runners, McKinsey \& Company.

Chadwick, C., \& Flinchbaugh, C. (2021). Searching for competitive advantage in the HRM-firm performance relationship. Academy of Management Perspectives, 35(2), 181-207.

Chen, Y., \& Xu, D. (2018) The Impact of the 'Artificial Intelligence Revolution' on Employment: Review and Prediction), SSRN Electronic Journal. 
Collins, C. J. (2021). Expanding the resource-based view model of strategic human resource management. The International Journal of Human Resource Management, 32(2), 331358.

Davenport, T. H., \& Kirby, J. (2016). Just how smart are smart machines?. MIT Sloan Management Review, 57(3), 21.

De Mendonça, A., Paulo, A., Rodrigues, A., Anderson, B., De Aragão, S., Amora, C., \& Couras Del Vecchio, R. (2018). Inteligência artificial-recursos humanos frente as novas tecnologias, posturas e atribuições. Revista Contribuciones a la Economía. ISSN, 16968360.

FraiJ, J., \& László, V. (2021). A literature Review: Artificial Intelligence Impact on the Recruitment Process. International Journal of Engineering and Management Sciences, 6(1), 108-119.

Frey, C. B., \& Osborne, M. A. (2017). The future of employment: How susceptible are jobs to computerisation? Technological forecasting and social change, 114, 254-280.

Hancock, B., Lazaroff-Puck, K., \& Rutherford, S. (2020). Getting practical about the future of work. The McKinsey Quarterly, 2, 123-132.

Huang, M. H., Rust, R., \& Maksimovic, V. (2019). The feeling economy: Managing in the next generation of artificial intelligence (AI). California Management Review, 61(4), 43-65.

Iqbal, F. M. (2018). Can Artificial Intelligence Change the Way in Which Companies Recruit, Train, Develop and Manage Human Resources in Workplace? Asian Journal of Social Sciences and Management Studies, 5(3), 102-104.

Jaiswal, A., Arun, C. J., \& Varma, A. (2021). Rebooting employees: upskilling for artificial intelligence in multinational corporations. The International Journal of Human Resource Management, 1-30.

Leveringhaus, A. (2018). What's So Bad About Killer Robots?. Journal of Applied philosophy, 35(2), 341-358.

Martens, B., \& Tolan, S. (2018). Will this time be different? A review of the literature on the Impact of Artificial Intelligence on Employment, Incomes and Growth.

MÉNIèRE, Y. A. N. N., Rudyk, I., \& Valdes, J. (2017). Patents and the Fourth Industrial Revolution: The inventions behind digital transformation. European Patent Office.

Muro, M., Maxim, R., \& Whiton, J. (2019). Automation and artificial intelligence: How machines are affecting people and places.

Mihai A. (2017). Chinese factory replaces $90 \%$ of human workers with robots. Production rises by $250 \%$, defects drop by $80 \%$. ZME Science. https://www.zmescience.com/other/economics/china-factory-robots-03022017

Nespoli, Z. B. (2004). Ciência, inteligência artificial e Pós-modernidade. Revista Diálogo Educacional, 4(13), 31-42.

Rajesh, S., Kandaswamy, U., \& Rakesh, A. (2018). The impact of Artificial Intelligence in Talent Acquisition Lifecycle of organizations. International Journal of Engineering Development and Research, 6(2), 709-717.

Rathi, D. R. (2018). Artificial intelligence and the future of HR practices. International Journal of Applied Research, 4(6), 113-116.

Reilly, P. (2018). The impact of artificial intelligence on the HR function.

Sparrow, R. (2007). Killer robots. Journal of applied philosophy, 24(1), 62-77.

Tegmark M. (2015) Autonomous weapons: an open letter from Al and robotics researchers.

Tschang, F. T., \& Mezquita, E. A. (2020). Artificial intelligence as augmenting automation: Implications for employment. Academy of Management Perspectives, (ja). 
INTERNATIONAL JOURNAL OF ACADEMIC RESEARCH IN BUSINESS AND SOCIAL SCIENCES

Vol. 11, No. 9, 2021, E-ISSN: 2222-6990 @ 2021 HRMARS

Wakefield, J. (2015). Intelligent Machines: The jobs robots will steal first. BBC News. Available via https://www.bbc.com/news/technology-33327659 